\title{
Uma reflexão sobre o processo de musealização: o patrimônio imaterial nos espaços museais
}

\author{
Priscila Maria de Jesus ${ }^{1}$
}

\begin{abstract}
Resumo: O presente artigo tem por objetivo levantar, de forma inicial, questionamentos sobre a musealização do patrimônio imaterial e o uso das novas tecnologias nos processos expositivos. Por meio de uma abordagem que busca trazer a história dos museus, o presente artigo faz um questionamento sobre o papel social dos museus em trazer para seus visitantes questões que perpassem a realidade do grupo social no qual está inserido.
\end{abstract}

Palavras-chave: Musealização, Patrimônio Imaterial, Oralidade, Novas Tecnologias.

\section{Abstract:}

This article aims to raise, questions about the musealization of intangible heritage and the use of new technologies in the exhibition process. Through an approach that seeks to bring the history of museums, this article makes an inquiry about the social role of museums in bringing visitors issues that permeate the reality of the social group in which it is inserted.

\footnotetext{
1 Possui graduação em Museologia pela Universidade Federal da Bahia (2006) e Mestrado em Crítica Cultural pela Universidade do Estado da Bahia (2012). Foi professora efetiva do curso de Museologia da Universidade Federal do Pará. Atualmente é professora do Núcleo de Museologia, da Universidade Federal de Sergipe. Atua nas áreas de Documentação, Musealização, Expologia e Arte.priscilamdj@gmail.com
} 
Keywords: musealization, Intangible Heritage, Orality, New Technologies.

\section{INTRODUÇÃO}

$O$ ato de pensar em como a Tradição Oral e o Patrimônio Imaterial são sistematicamente representados dentro dos espaços museais pode suscitar uma série de questionamentos e possibilidades, sobretudo quando da possibilidade de representar o imaterial com o material.

Embora pensar uma prática de preservação do patrimônio Imaterial só tenha sido legitimada a partir do ano de 2000 no Brasil e 2003 na UNESCO, é importante salientar que todo objeto materializado tem sua parcela de imaterialidade presente e, que o registro do Patrimônio Imaterial veio para manter e preservar manifestações, sobretudo do dito popular, que ainda se mantêm na contemporaneidade.

Mas, o que se vê nos espaços museais, em sua grande maioria, é uma falta de abordagem e problematização das questões sociais dentro dos museus e em suas exposições, no qual a realidade dos grupos sociais e seus anseios e demandas não são representados ou vistos.

A partir dessas questões, o presente artigo visa abordar, de forma inicial, por meio de um relato histórico da evolução dos museus, que esse viés pouco voltado para o social sempre esteve presente no discurso expositivo dos museus.

\section{UMA BREVE HISTÓRIA DOS MUSEUS}

A evolução da noção de museu, que inicia como a de um espaço de guarda, que se caracteriza com o surgimento dos gabinetes de curiosidades ou câmaras das maravilhas. Mas, é importante destacar que a palavra museus surgiu na Grécia antiga como mouseion, a Morada o Templo das Musas, 
que pode ser visto como uma combinação de Templo e espaço de reflexão, voltada para as artes e o saber filosófico, uma vez que as Musas comandavam as artes e a criatividade humana.

En un principio, la palabra museo se utilizaba con dos connotaciones diferentes. Por una parte, la palabra museum, proveniente del griego museion, significaba 'lugar dedicado a las Musas' (locus musis sacer). Su dimensión mitológica presentaba a dicho lugar habitado por nueve musas hijas de Zeus y Mnemosyne (la Memoria), consideradas diosas protectoras de la poesía, de las ciencias y las artes, que tienen como tarea enseñar a los humanos aquellas cosas curiosas y dignas de ser conocidas, convirtiéndose, así, en fuente y origen del museo. (HERNÁNDEZ HERNÁNDEZ, 2006, p. 18, grifos da autora).

Segundo a museóloga Tereza Scheiner (1999) após uma discussão sobre a origem das Musas, filhas de Zeus com Mnemosine, informa que estas não habitavam em um espaço edificado, mas se faziam presentes quando invocadas pelo ser humano através da palavra, do canto. Scheiner sugere que a palavra mouseion seria, "[...] uma interpretação equivocada do termo Mousàon ou Mousaion (pelas Musas) [...]" (1999, p. 137, grifos da autora). Na discussão sobre a etimologia da palavra museu, a autora começa a fazer um apanhado do próprio significado do mito enquanto representação de algo, uma fala, uma mensagem que buscava se passar e utilizava a universo mitológico para exemplificar, onde as noções de tempo e espaço se interligavam. Ou seja, a ideia de museu não estava relacionada a um espaço específico ou uma coleção, mas sim na relação entre o ser humano e a realidade. Embora a autora utilize a noção de realidade, essa se configura de forma parcial e de segregação, uma vez que, independente da interpretação dada a posteriori o mouseion é um espaço excludente, no qual apenas os cidadãos gregos (homens, adultos e com bens) participam. Assim, esse espaço 
surge como um local de indagação de um saber filosófico e não como um espaço de questionamento da condição social.

O primeiro museu que se tem notícia foi o mouseion e a Biblioteca de Alexandria, a qual reunia estudiosos para discutir sobre as ciências. Nesse espaço buscava-se ensinar tudo relacionado à religião, mitologia, astronomia, filosofia, zoologia e etc., eram reunidos tanto objetos de arte como objetos cirúrgicos e astronômicos, peles de animais raros e materiais minerais dentre outros, além de possuir um anfiteatro e um observatório. Essa ideia de compilação do saber ficou ligada a palavra "museu", dispensando mesmo as instalações físicas.

Foi Roma a grande capital do colecionismo na Antiguidade Clássica, com bens oriundos de espólios de guerra e de conquistas, a capital romana passou a exibir e competir entre seus filhos mais ricos, as monumentais coleções de obras de artes. Essas coleções eram abertas entre os nobres e demonstravam além do poderio dos inimigos conquistados por Roma como também bom gosto e requinte.

No Renascimento, o termo museu começou a determinar as obras de caráter enciclopédico, talvez por referência ao mouseion de Alexandria. Publicaram-se, até o século XIX, compilações com qualquer tema e com o título de Museus, a exemplo do Poetical Museum (coletânea de poemas e canções). Somente com o passar do tempo é que estudiosos passaram a observar esse fenômeno do colecionismo e a dividir as coleções em categorias.

No século XIX, no Brasil, os museus começar a ser criados a partir de coleções da nobreza e oriundos dos antigos gabinetes de curiosidades, mas estes continuam a manter sua função precípua de mostrar o exótico, o diferente, sem uma preocupação com os princípios expográficos (construção de uma narrativa expositiva) e documentais (enquanto a criação de um sistema de documentação do acervo, entre as quais a facilitação da 
recuperação da informação e controle do acervo da instituição), pois eram "instituições dedicadas à coleção, preservação, exibição, estudo e interpretação de objetos materiais." (SCHWARCZ, 1993, p. 68).

Entre as décadas de 1920 e 1930 tem-se fim a era dos museus nacionais no Brasil, sobretudo as pesquisas de cunho evolucionista e baseadas em teorias raciais, mas agora eles entram em cena sob uma nova óptica, como depositários dos exemplares apreendidos pela polícia provenientes de terreiros de candomblés, como relata Lody:

Também nas cidades do Salvador, Recife, Rio de Janeiro e outras durante o Estado Novo (1937), foram registrados abusos de autoridade policial, resultando em invasões de terreiros e apreensão de objetos, levados, então, para delegacias policiais, hospitais psiquiátricos e, posteriormente, utilizados como documentos de marginalidade e loucura, resultantes da danosa mistura de raça. (LODY, 2005, p. 24)

Essa perseguição policial, que também estava presente no nível político está registrada nas crônicas e jornais presentes até hoje nos institutos históricos e geográficos por toda a nação.

Se proliferam museus no Brasil e no mundo, onde mesmo quando tentam abordar a realidade de grupos sociais, deste modo, ao questionar: o que os museus do século XXI estão adquirindo? Teremos como resposta, o que foi no século XX, no XIX... Para se repensar esse museu do século XXI e suas práticas comunicacionais é necessário, também, que se reveja os seus objetivos, abrangência, formas de aquisição e a adequação de linguagens e incorporação de novas tecnologias.

Ao se pensar no processo de formação do patrimônio dentro desses espaços museais contemporâneos, percebe-se que deveria haver uma relação formada por uma estrutura cíclica entre ser humano-objeto-ser humano, uma vez que este objeto 
produzido pelo ser humano é selecionado, valorado para depois retornar para ele-(a), agora como documento. Nesse ciclo destaca-se um dos processos de valoração do objeto/documento que na Museologia é conceituado como musealização.

\section{A MUSEALIZAÇÃO DO PATRIMÔNIO IMATERIAL}

$O$ ato de musealizar é composto por procedimentos básicos, pelos quais um bem (material ou imaterial) adquire 0 status de patrimônio: "[...] aquisição, pesquisa, conservação, documentação e comunicação" (CURY, 2005, p. 26). Essas ações que compõem as atividades desenvolvidas pelos profissionais da área museal, podem ser realizadas com objetos dos mais diversos tipos e suportes, e consistem na análise das etapas pelas quais um objeto passa até se tornar patrimônio musealizado, ou seja, a sua retirada de seu contexto primário para que se integre em uma nova categoria de análise, agora como objeto museal.

Para compreender a legitimação de um patrimônio é necessário entender seu processo de musealização, ou melhor, no que consiste musealizar algo, que de uma forma inicial, pode ser entendida como a passagem do objeto para documento, ou seja, sua retirada de uma configuração real (sua função precípua) para se tornar um bem patrimonial. Em uma publicação do Comitê Internacional de Museologia do Conselho Internacional de Museus (ICOFOM) e Subcomitê Regional do Comitê Internacional de Museologia para a América Latina e o Caribe (ICOFOM LAM) comitês de trabalho e de debate sobre as questões teóricas da Museologia do ICOM, Desvallées (2000) define musealização como:

Opération tendant à extraire une (ou dês) vraie(s) chose(s) de son (leur) milieu naturel ou culturel d'origine et à lui (leur) donner um statut muséal. C'est le constat de ce changement de nature qui a conduit Zbyneck STRANSKY, en 1970, à proposer de dénommer <<musealia >> (en français, $<<$ muséalies>>) les objets de musées. La muséalisation commence par une étape de séparation ou de suspension. 
(Desvallées, 2000, p. 71)

A suspensão consiste na retirada do objeto, que pretende ser musealizado, do seu local de origem (seu meio) para se inserir nos espaços museais e adquirirem a função de objeto de museu ou documento. Essa separação do objeto faz com que ele adquira novas funções, como a de comunicar ou entreter. É o que Francisco Ramos explicita ao dizer:

Ninguém vai a uma exposição de relógios antigos para saber as horas. Ao entrar no espaço expositivo, o objeto perde seu valor de uso: a cadeira não serve de assento, assim como a arma de fogo abandona sua condição utilitária. Quando perdem suas funções originais, as vidas que tinham no mundo fora do museu, tais objetos passam a ter outros valores, regidos pelos mais variados interesses. (RAMOS, 2004, p. 17)

A suspensão busca inserir o objeto no espaço do museu, ou lhe dar um tratamento museal, com a sua retirada de seu contexto original e de sua função precípua para se inserir em uma nova lógica, agora a patrimonial. Esse objeto passa então a ser um testemunho de uma determinada realidade, embora seja necessário afirmar que esse objeto/testemunho se constitui por si mesmo na realidade, mas apenas uma das possibilidades de interpretação desta.

La musealización, como processo científico, abarca el conjunto de actividades del museo: el trabajo de preservación (selección, adquisición, gestión, conservación), de investigación (del que surge la catalogación) y de comunicación (por medio de la exposición, las publicaciones, etc.) o bien, desde otro punto de vista, las actividades vinculadas a la selección, la tesaurización y la presentación de aquello que se ha transformado en musealia. No obstante, el trabajo de musealización solamente conduce a dar una imagen que no es más que un sustituto de esa realidad a partir de la cual los objetos son seleccionados. (DESVALLÉES; MAIRESSE, 2010, p. 51). 
Musealizar um objeto não se resume em colocá-lo no museu, este se insere em uma rede de relações e procedimentos técnicos, transformando-o em testemunhos de uma determinada cultura e sociedade, passando a se configurar como um suporte da informação, o qual será salvaguardado, pesquisado e comunicado. Essas ações buscam compreender a realidade do objeto, sem atestar uma realidade única e incontestável, mas compreender o objeto como gerador de informação, além da sua preservação e manutenção para uma posteridade.

A musealização insere o objeto/documento e a instituição museu em uma lógica patrimonial que tende para uma reflexão aprofundada do mesmo, com ênfase na pesquisa. No entanto, a todo o momento, quando se fala em musealização, relaciona-se com o objeto e esse, geralmente materializado. No entanto, como se musealizar algo que não é tangível?

A ampliação da noção de patrimônio, sobretudo com a globalização, impulsionada pelos países asiáticos e africanos que tem por base essencial a interação do conhecimento através da oralidade, que a partir da Recomendação da Salvaguarda da Cultura Tradicional e Popular, de 1993, abre possibilidades para se pensar o ser humano como patrimônio, ou seja, tesouro humano vivo. Este culmina em 2003, com a Convenção para a salvaguarda do patrimônio cultural imaterial, a qual prevê o registro do Patrimônio Imaterial Mundial (festas, celebrações, lugares, saberfazer, entre outros).

No entanto, o que se vê quando se musealiza o patrimônio imaterial, são seus correlatos materiais, ou seja, objetos que podem expressar a imaterialidade do patrimônio em questão. Assim, traz-se como exemplos, dois museus brasileiros que abordam patrimônio imaterial, o Museu do Círio, localizado da cidade de Belém, no estado do Pará, e o Museu da Língua Portuguesa, na cidade de São Paulo.

O Museu do Círio de Nazaré foi criado em 1986, mas foi reinaugurado em dezembro de 2002. Embora a ideia do museu tenha se concretizado antes do registro da celebração como 
Patrimônio Imaterial, pelo Instituto do Patrimônio Histórico e Artístico Nacional - IPHAN - que ocorreu em 2004 - o museu buscou, inicialmente, mostrar para o público a devoção do povo paraense a Nossa Senhora de Nazaré.

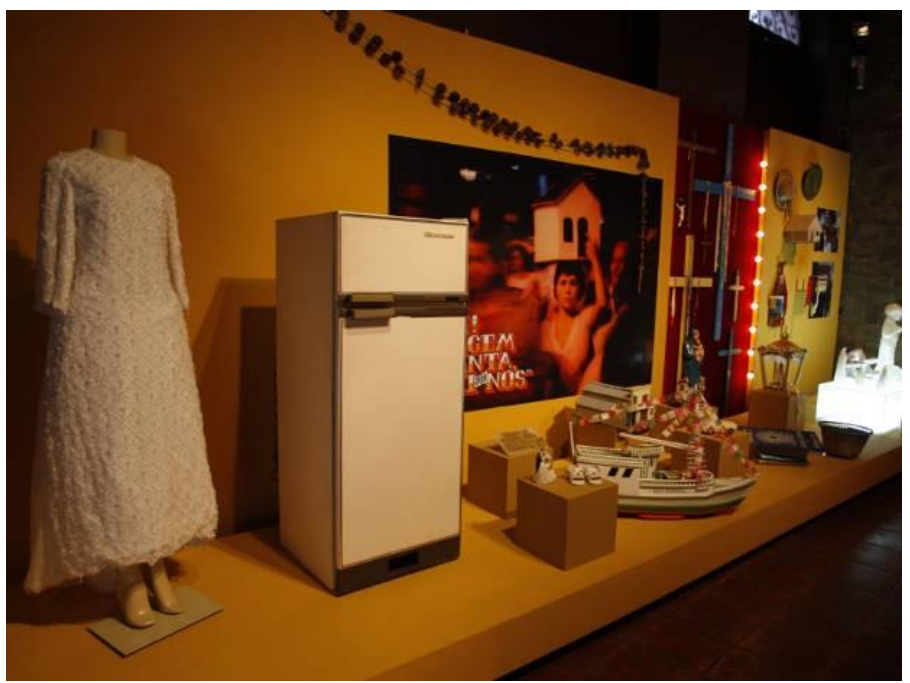

Figura 01 - Museu do Círio. Fonte: Google

A Figura 01 apresenta parte da exposição existente no Museu. O primeiro módulo é composto pelos ex-votos que foram deixados na catedral ou ainda são deixados como graça alcançada. Entre os objetos de cera, característico dos ex-votos nota-se a presença também de um vestido de noiva e uma geladeira, entre os objetos deixados.

Nessa sala expositiva (Figura 02) é possível ver, em primeiro plano, vitrine com o manto da imagem de Nossa Senhora de Nazaré (um novo manto é confeccionado para cada novo Círio). Na parede lateral, na vitrine maior, há a os estandartes da procissão e ao fundo, uma vitrine com vários exvotos de cera e à esquerda imagem da passagem da corda durante o Círio. 


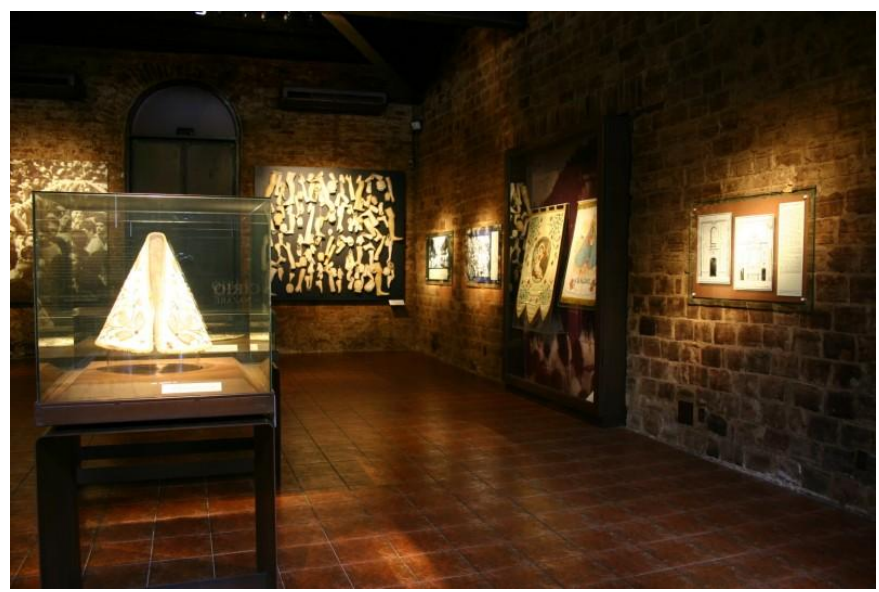

Figura 02 - Museu do Círio. Fonte: Google

Uma vitrine contendo vestidos e asas usadas por crianças durante a procissão pontua em sua legenda o momento a partir do qual se tornou tradição a presenças das crianças vestidas de anjo, bem como caráter involuntário destas crianças no pagamento de promessas feitas por seus pais e parentes próximos.

Em um aparelho de TV é projetado um vídeo de aproximadamente quinze minutos, que mostra imagens dos devotos que pagam sua promessa fazendo o percurso da procissão segurando a corda que puxa a berlinda. Neste vídeo há também o caráter individual e o coletivo desses promesseiros no momento em que cada um busca ter acesso a um pedaço da corda para segurar e seguir a procissão. Em texto são apresentados a Santa, a berlinda e a corda, como os principais elementos das procissões do Círio de Nazaré, informando o visitante sobre a função destes e como cada um desses elementos ganhou significado devocional atual. Deste modo, nota-se que o museu busca contextualizar para o visitante o desenvolvimento da festividade localizando no tempo a inserção dos seus principais elementos.

O museu se propôs a narrar, por meio dos objetos 
materializados que compõem a devoção a Nossa Senhora de Nazaré e á celebração do Círio, realizado todo mês de outubro. No entanto, ao se andar pela exposição e perceber os objetos que são expostos e a narrativa que foi construída, fica latente que o objetivo desta consiste em mostrar os fatos - os elementos que compõem o Círio de Nazaré -, sem motivar no visitante uma abordagem mais crítica sobre a festividade.

A exposição mostra ainda duas festas que ocorrem durante o Círio, já há algumas décadas e mobiliza significativo número de participantes, porém não guardam o mesmo sentido religioso, são o Arrastão do Pavulagem e a Festa da Chiquita. Esta consiste em um grupo de homossexuais, travestis, transgêneros e simpatizantes, que são representados por fotos e uma pequena escultura de um veado de ouro, instalação que faz uma alusão à Festa da Chiquita, assim encerrando o circuito expositivo do museu.

Deste modo, a exposição de longa duração do Museu do Círio em Belém do Pará, busca contemplar os vários sentidos da festa, do sagrado ao profano. Mas, embora o tema do museu seja uma celebração imaterial, o que se percebe é o foco na materialidade por meio dos objetos expostos, sem um aprofundamento ou questionamentos sobre a festa, o ato da fé ou a presença das festividades pagãs no seio de uma festa católica cristã.

O Museu da Língua Portuguesa foi inaugurado no ano de 2006, na Estação da Luz, e contou com o maior orçamento utilizado até então para uma montagem expositiva. Também visto como um museu tecnológico, uma vez que sua exposição está quase que completamente pautada nas novas tecnologias. Objetivando mostrar a língua portuguesa e sua importância na nossa sociedade, o museu busca valorizar e difundir o português, além de ter áreas voltadas para as línguas indígenas faladas no território nacional. 


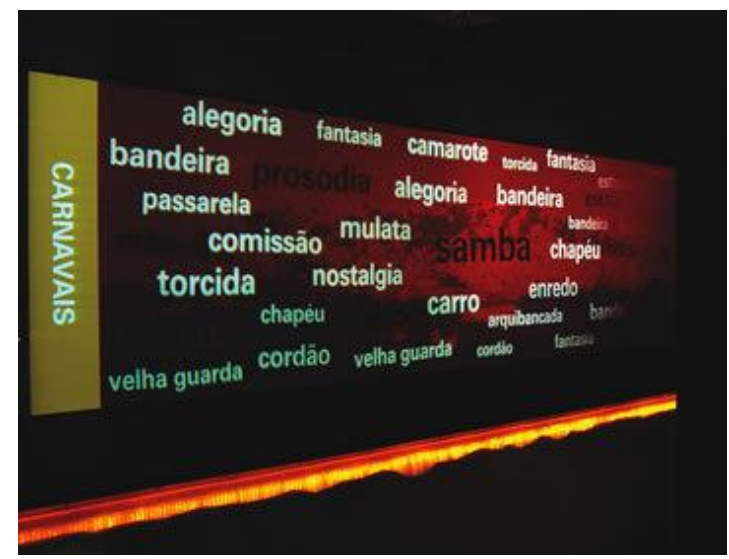

Figura 03 - Parede do Museu da Língua Portuguesa. Fonte: Google

Na Figura 03 é possível perceber uma grande parede com várias palavras projetadas que remetem para o tema central "Carnaval". O intuito de mostrar a língua como patrimônio imaterial nacional e suas variações permeiam todo o circuito expositivo.

A Figura 04 traz mais um módulo expositivo que apresentas as línguas indígenas faladas em território nacional na atualidade. É possível perceber em toda a exposição essa relação direta com as novas tecnologias como meio de comunicação, assim:

Seguindo a tendência de incorporar novas tecnologias, novas linguagens e novos temas, houve a proliferação de projetos de História Oral em museus de diversos países: o Ellis Island Immigration Museum (Nova lorque); o Museu da Diáspora (Israel); o National Sound Arquive (Londres)/ o Museu da Imagem e do Som-MIS, o de São Paulo e o do Rio de Janeiro, o Museu Marc Chagall (Porto Alegre) e mais recentemente o Memorial do Imigrante/Museu da Imigração, em São Paulo, apenas para citar alguns exemplos. Vale também destacar a criação de diversos museus, 
departamentos de memória, por empresas e instituições públicas e privadas, que se dedicam ao trabalho de resgate e preservação da memória histórica. (FREITAS, 2002, p. 105-6).

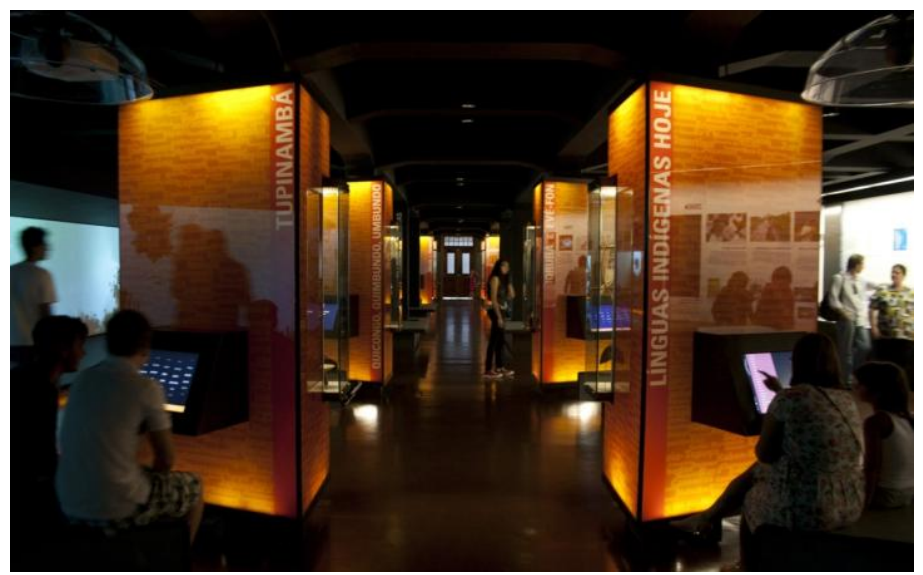

Figura 04 - Museu da Língua Portuguesa. Fonte: Google

Percebe-se que há uma tendência na contemporaneidade para o uso das ferramentas tecnológicas, algumas vezes até mesmo como se o simples fato de possuir tais recursos compensasse a falta de um aprofundamento de questionamentos ou informações que deveriam estar ao longo da exposição. Um tema tão complexo e ao mesmo tempo tão rico como a língua portuguesa poderia ser o viés de discussões de inúmeras questões sociais e históricas do Brasil, o que não acontece. A exposição fica centrada em mostrar essa língua tendo como grande viés o uso das tecnologias de ponta, fazendo com que o observador se pergunte qual o real objetivo da exposição.

A excessiva utilização dos recursos tecnológicos, ou a sua má, dentro dos espaços museais são perceptíveis nas exposições existentes, onde os requisitos interativo e tecnológico são sinônimos de um alto índice de visitação e públicos nos museus. Os museus são espaços a serviço da sociedade e como tal deveriam, também "[...] refletir a 
sociedade que representa." (FREITAS, 2002, p. 107). Esse caráter social perpassa, além do que é visto nas exposições, nos processos internos, sobretudo no acervo que deveria ser adquirido. Assim, dentro do viés de acervos com suporte digital, destaca-se o uso de registros orais. Pouco utilizado nos museus, o relato de pessoas diretamente ligadas à história do objeto de museu (seja dos antigos donos dos objetos, participantes de festividades e etc.) deveria ser priorizado no ato de aquisição de um determinado acervo, por se constituir uma fonte de informação privilegiada da história do objeto. Assim, poucos museus fazem uso da oralidade dentro de suas exposições ou como fonte de pesquisa.

\section{ALGUMAS CONSIDERAÇÕES INICIAIS}

Pensar as exposições, os museus e seus acervos como uma ferramenta de decisão e engajamento social, passível de mostrar os anseios e sonhos de um determinado grupo ainda é uma realidade distante de muitos museus. Mas o que se tentou aqui foi mostrar que na própria história do museu esse viés social não foi evidenciado, se atendo a outras questões diretamente ligadas com o objeto materializado, mesmo quando trabalhando com manifestações imateriais.

Os museus podem ser ferramentas de mudança social, como idealizado na década de 1960 pela Nova Museologia, o museu tem sim um caráter social, mas está escondido em tantos outros recursos e histórias, que não fica aparente ao seu público.

Uma das possibilidades de ampliar o debate que envolve a musealização do patrimônio imaterial e o uso das novas tecnologias nos processos expositivos é a adoção da História Oral aplica à exposição desde a sua concepção, pois trata-se de uma metodologia interdisciplinar tanto em sua construção quanto nas possibilidades de sua aplicação (ALBERTI, 2011. p. 156). 
Cabe ao museu se renovar, se reinventar, se mostrar. Seja por meio de sua exposição ou sua equipe. A mudança de terminologias não implica necessariamente na mudança de direção do museu, mas é o que se tem visto.

Vamos dar ao museu as vozes que devem ser priorizadas: a da sua sociedade.

\section{REFERÊNCIAS}

ALBERTI, Verena. História dentro da história. In. Fontes Históricas. Carla Bassanezi Pinsk (Org.). 3a Ed. Contexto, São Paulo, 2011.

CURY, Marília Xavier. Exposição: concepção, montagem e avaliação. São Paulo: Annablume, 2005.

DESVALLÉES, André; MAIRESSE, François (Coor.). Conceptos claves de la Museología. Traducido por Armida Córdoba. Paris: Armand Colin, 2010.

DESVALLÉES, André (Coor.). Terminología Museológica: Proyecto permanente de investigación. ICOFOM/ICOFOM LAM, mayo, 2000.

FREITAS, Sônia Maria de. História Oral: Possibilidades e procedimentos. São Paulo: EDUSP, 2002.

HERNÁNDEZ HERNÁNDEZ, Francisca. Planteamientos teóricos de la museología. Gijón: TREA, 2006.

LODY, Raul. O negro no museu brasileiro: construindo identidades. Rio de Janeiro: Bertrand Brasil, 2005.

RAMOS, Francisco Régis Lopes. A danação do objeto: o museu no ensino de história. Chapecó: Argos, 2004.

SCHEINER, Tereza Cristina. As bases ontológicas do museu e da Museologia. In: Anais do VIII Encuentro Regional do ICOFOM LAM, 1999, p. 133-164.

SCHWARCZ, Lilia Moritz. O espetáculo das raças: cientistas, instituições e questão racial no Brasil 1870-1930. 4. reimp. São Paulo: Companhia das Letras, 1993. 


\section{Referência das Figuras:}

Figura 1 http://s2.glbimg.com/Szm9el8-DSesWAEPLA5GLL BcmEK4ESHBTncJ9g|1X4tloz-HdGixxa 8qOZvMp3w/s.glbimg .com/jo/g1/f/original/2012/10/21/exvotos 1.jpg

Figura 2 - http://mondobelem.files.wordpress.com/2008 L12/mondobelemcom museu cirio03.jpg

Figura 3 - http://blog.portalpositivo.com.br/nossa lingua/files /2013/02/ museu -da-lingua-portuguesa2.jpg

Figura 4 - http://fotos.kvinicius.com.br/public/cache photo /e3242fe777fbc71d59c172756c345f13.jpg 